\title{
Webcam network and image database for studies of phenological changes of vegetation and snow cover in Finland, image time series from 2014 to 2016
}

\author{
Mikko Peltoniemi ${ }^{1}$, Mika Aurela ${ }^{2}$, Kristin Böttcher ${ }^{3}$ Pasi Kolari $^{4}$, John Loehr ${ }^{5}$, Jouni Karhu ${ }^{6}$, \\ Maiju Linkosalmi ${ }^{2}$, Cemal Melih Tanis ${ }^{2}$, Juha-Pekka Tuovinen ${ }^{2}$, and Ali Nadir Arslan ${ }^{2}$ \\ ${ }^{1}$ Natural Resources Institute Finland (Luke), Latokartanonkaari 9, 00790, Helsinki, Finland \\ ${ }^{2}$ Finnish Meteorological Institute, Erik Palménin aukio 1, 00560 Helsinki, Finland \\ ${ }^{3}$ Finnish Environment Institute (SYKE), Mechelininkatu 34a, 00251 Helsinki, Finland \\ ${ }^{4}$ Department of Physics, University of Helsinki, P.O. Box 68, 00014 Helsinki, Finland \\ ${ }^{5}$ Lammi Biological Station, University of Helsinki, Pääjärventie 320, 16900 Lammi, Finland \\ ${ }^{6}$ Natural Resources Institute Finland (Luke), Paavo Havaksen tie 3, 90014 Oulun yliopisto, Finland \\ Correspondence: Mikko Peltoniemi (mikko.peltoniemi@luke.fi) \\ and Ali Nadir Arslan (ali.nadir.arslan@fmi.fi)
}

Received: 30 June 2017 - Discussion started: 10 August 2017

Revised: 27 November 2017 - Accepted: 29 November 2017 - Published: 25 January 2018

\begin{abstract}
In recent years, monitoring of the status of ecosystems using low-cost web (IP) or time lapse cameras has received wide interest. With broad spatial coverage and high temporal resolution, networked cameras can provide information about snow cover and vegetation status, serve as ground truths to Earth observations and be useful for gap-filling of cloudy areas in Earth observation time series. Networked cameras can also play an important role in supplementing laborious phenological field surveys and citizen science projects, which also suffer from observer-dependent observation bias. We established a network of digital surveillance cameras for automated monitoring of phenological activity of vegetation and snow cover in the boreal ecosystems of Finland. Cameras were mounted at 14 sites, each site having 1-3 cameras. Here, we document the network, basic camera information and access to images in the permanent data repository (http://www.zenodo.org/communities/phenology_camera/). Individual DOI-referenced image time series consist of half-hourly images collected between 2014 and 2016 (https://doi.org/10.5281/zenodo.1066862). Additionally, we present an example of a colour index time series derived from images from two contrasting sites.
\end{abstract}

1

Year-to-year variation in the phenological cycle of seasonal ecosystems is large. The snow cover and the timing of snowmelt vary considerably from year to year. For example, in northern and high-elevation ecosystems, vegetation follows the temporal variation of temperatures, and budburst dates can vary by 40 days (Häkkinen, 1999), but our ability to predict this variation is limited (Basler, 2016). Consequently, phenology remains among the key components causing uncertainties in our estimates of vegetation carbon balances (Richardson et al., 2013). Obviously, more monitoring data are required for improving the understanding of the sources of phenological variation and to directly support its monitoring, as present methods for monitoring plant phenology and snow cover in the field are laborious and costly. Consumergrade cameras provide an interesting opportunity to monitor the seasonal cycle of ecosystems because they record structural information at high spatial and temporal resolution, and in doing so, time series of images can provide useful information about temporal changes in ecosystems at a low cost.

In recent years, the ecological community has started to collect image time series for the purposes of phenological analysis (Richardson et al., 2007). In these analyses, typi- 
cally some sub-regions are used to track colour changes in time, using indices representing chromatic changes in the target scene, which are related to phenological changes of leaf colour, quantity (emergence and abscission), morphology and prevailing conditions at the site. Analyses of chromatic changes and associated phenological transition dates can be easily automated by using statistical methods that identify break points in time series (Elmore et al., 2012; Klosterman et al., 2014; Wingate et al., 2015). Although colours of the images in the time series are affected by illumination angle, cloud cover and camera type, much of the potential problems in phenological time series can be largely avoided by using images from similar environmental conditions, and by selecting a subset of images for analyses and applying colour index appropriately. Green chromatic coordinate, $\mathrm{GCC}=\mathrm{G} /(\mathrm{R}+\mathrm{B}+\mathrm{G})$, on the other hand, is a fairly robust index of colours, because the opposing changes in red and blue partially balance each other out over the course of the day (Wingate et al., 2015). GCC has been used in phenological analyses by estimating a mean using midday images and then averaging the estimates over 1-3 days (e.g. Sonnentag et al., 2012; Linkosalmi et al., 2016).

Cameras have been deployed on a range of ecosystems, including deciduous and mixed species ecosystems (Richardson et al., 2007; Ahrends et al., 2009; Sonnentag et al., 2012; Mizunuma et al., 2013), grasslands (e.g. Migliavacca et al., 2011), peatlands (Westergaard-Nielsen et al., 2013; Peichl et al., 2015; Linkosalmi et al., 2016) and coniferous forests (Nagai et al., 2012; Linkosalmi et al., 2016). Budburst and leaf senescence of deciduous species and their relationship with $\mathrm{CO}_{2}$ exchange have been a focus in a number of studies (Richardson et al., 2007; Ahrends et al., 2009; Sonnentag et al., 2012; Mizunuma et al., 2013; Wingate et al., 2015). Reasons for plant colour changes have been related to the variation of green biomass, and also to changes in the biochemical properties of leaves occurring over the season (Keenan et al., 2014; Yang et al., 2014). While more detailed radiative transfer analyses may be required to confirm the consequences of pigment and other changing properties of leaves on the colours (Wingate et al., 2015), the clearest phenomena such as budburst and autumn colour peaks can already be extracted with simple time series and break point analyses with fairly good accuracy (e.g. Sonnentag et al., 2012; Klosterman et al., 2014; Wingate et al., 2015; Peltoniemi et al., 2018). Besides vegetation monitoring, time lapse images have been used in snow cover monitoring. Salvatori et al. (2011) developed a method for analysing snow cover changes based on the thresholding of blue channel histograms. The method has been recently tested also in northern boreal Finland (Arslan et al., 2017). Perhaps the most obvious use of camera time series stems from the possibility of using image archives for documenting the site history. As such, they provide supportive information on the ambient conditions, i.e. information about weather, vegetation and unexpected disturbances.
Given the wealth of features that can be extracted from image time series, it is not surprising there is a large interest in using them as ground references for Earth observation (EO) products. A particular benefit of cameras is that they can provide a continuous time series of reference observations, as they are not or are rarely occluded by clouds. Previous research has already shown good correspondence between the camera-based and EO phenology products (Zhang et al., 2006; Morisette et al., 2009; Elmore et al., 2012; Hufkens at al., 2012; Klosterman et al., 2014).

The full benefits of using cameras in ecosystem monitoring are reached when information from multiple cameras are analysed together, and thus many of the cameras have been set up in smaller or larger networks of sites. In the US, PhenoCam network has collected time lapse images for several years (Richardson et al., 2009; http://phenocam.sr. unh.edu). In Japan, researchers have collected images from atmosphere-ecosystem carbon flux sites within the framework of the Japan Phenological Eyes Network (PEN; Nasahara and Nagai, 2015; http://pen.agbi.tsukuba.ac.jp) with the aim of linking them to other remote sensing and field observations. The European network of carbon flux sites operate cameras at least in 50 sites (Wingate et al., 2015). Phenological camera monitoring is being more widely implemented within the framework of the US National Ecological Observatory Network (NEON) and the European Union's Integrated Carbon Observation System (ICOS). Many networks (e.g. Australian Phenocam Network, http://www.phenocam. org.au) and ICOS are providing data online by request and/or have plans for open distribution of images (Brown et al., 2016).

Keeping the benefits of using cameras for ecosystem close range remote sensing in mind, and in order to contribute to the growing body of cameras, which are monitoring the ecosystems of the Earth, we established a network of cameras for monitoring boreal ecosystems in Finland. Here, we document the sites of this monitoring network including the equipment used and the availability of data in open repositories, as well as reporting our first-hand experiences while setting up the network and envisage further development needs for the network. We have made image data public from 27 cameras at 14 sites in the Zenodo data archive (https://www.zenodo.org/), which is appended with metadata sheets fulfilling the criteria developed by Brown et al. (2016) for integrated camera networks. Additionally, we prepared analyses of Sun angle effects on the annual course of GCC at two contrasting sites, one located in the southern boreal region and one in the subarctic region where days are short. We analysed two types of targets in the southern site, namely a broad-leaved and a conifer tree which fundamentally differ in canopy and leaf morphology and annual leaf period (seasonal vs. evergreen). In the subarctic site, we also analysed colour changes of birch and wetland grasses. 


\section{Network of cameras}

\subsection{Cameras and camera configurations}

All cameras are set to a fixed white balance and automatic exposure, targeted northwards where feasible depending on the view and mounting options, and triggered for halfhourly submission of snapshots to an FTP server, excluding the night hours. Images are taken at maximum resolution allowed by the camera $(2594 \times 1944)$, except in Hyytiälä where they are taken at quarter of the maximum resolution allowed by the camera $(1024 \times 768)$. Image JPEGs are of highest possible quality. Most of the sites and analyses of this study used image time series acquired with StarDot NetCam SC5 cameras, while more recently also an AXIS P1357E camera was installed at one of the sites (Paljakka). We did not expect colour reproduction of cameras to be standardized and calibrated, i.e. comparable across cameras, so we allowed some variation in the camera settings by local conditions. In StarDot cameras, we modified the R, G and B channel amplification settings from the default settings for local scenes so that cameras produced visually approximately realistic colours. These settings were kept fixed thereafter, and they are reported in the camera datasheet (https://doi.org/10.5281/zenodo.1066862; Peltoniemi et al., 2017). In AXIS P1357E, white balance was set to fixed ("Fixed outdoor 1" in the camera menu). Pixel digital numbers are not thus directly comparable across cameras, but allow camera-specific analyses of, for example, the temporal development of digital numbers and indices based on them. Iris and zoom were fixed to camera specific values depending on the view of the camera. Cameras adjust for brightness of the images automatically. Selected cameras also have grey reference plates to monitor the stability of colour reproduction of the cameras.

\subsection{Sites}

The locations of camera monitoring sites ranged from the hemiboreal (Tvärminne) to the northern boreal (Kaamanen) phytogeographical zone (Fig. 1, Table 1). All sites belong to the subarctic climate zone (Dfc) according to Köppen's climate classification, except the Tvärminne site, which is situated in the warm-summer humid continental climate zone (Dfb). The start and duration of continuous snow cover varies along the climate gradient from southwest to north in Finland. Permanent snow cover arrives on average (normal period 1981-2010) in October and January and melts in May and March for the Kaamanen and Tvärminne sites, respectively. The thermal growing season begins when mean daily temperatures exceed $5{ }^{\circ} \mathrm{C}$ at the end of April in southern Finland and at the end of May in northern Lapland. Temperatures decrease below $5{ }^{\circ} \mathrm{C}$ ending the thermal growing season at the end of September in the north and in late October or the beginning of November in southwestern Finland.

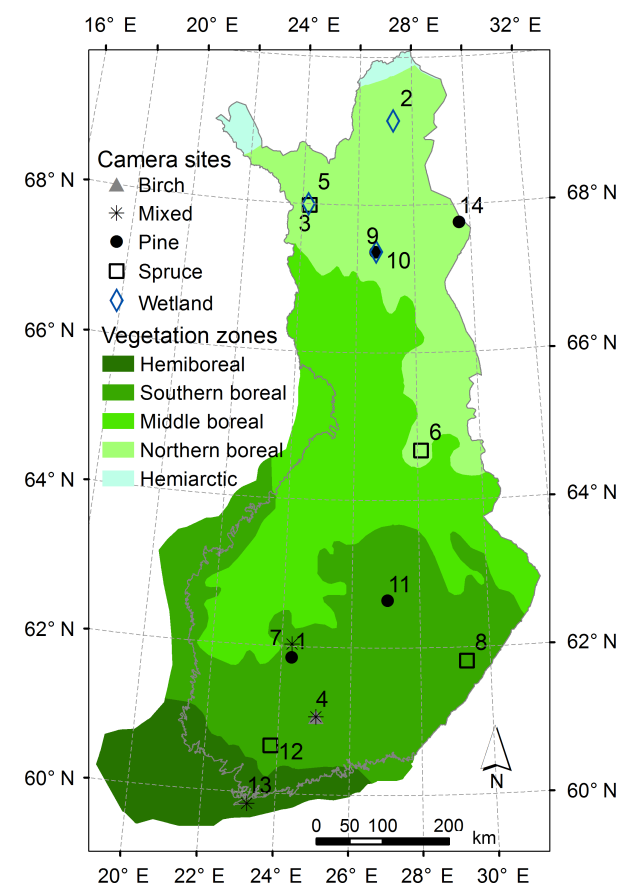

Figure 1. Sites in the phenological camera network, status end of 2016. Numbers refer to sites in Table 1. Data sources: Country border (c) ESRI, Vegetation zones (C) SYKE, 2015.

The camera monitoring sites include ICOS and other eddycovariance sites, LTER (Long-Term Ecosystem Research) and ICP Forests Level II sites, and other sites with previous phenological monitoring. Some sites are highly instrumented and intensively monitored ecosystem research sites such as Hyytiälä SMEAR II, Värriö SMEAR I and Sodankylä eddy covariance sites, while others are less intensively monitored. For most of the sites there is at least a meteorological station, and varying number and types of ancillary monitoring measurements. Data from the Finnish Meteorological Institute (FMI) meteorological stations can be freely downloaded from the FMI open data portal (https: //en.ilmatieteenlaitos.fi/open-data), e.g. by using a user interface "FMI weather data downloader" (https://github.com/ Tumetsu/FMI-weather-downloader).

We installed 1-3 cameras to the monitoring sites. The number of cameras depended on the canopy conditions at the site (Table 1; see also http://monimet.fmi.fi/?page=Cameras). The cameras view the canopy, ground and/or a wider landscape (Fig. 2). Some cameras were mounted closer to individual tree crowns, thus narrowing the region of interest (ROI) of image analysis to the target trees without confounding contribution from the ground. The cameras mounted below the canopy monitor the phenology of understorey vegetation and snow cover. At the wetland sites, a single camera fulfils all these purposes. Many of the cameras allow defining multiple ROIs to monitor various species and phenomena at the same time. 
Table 1. Basic information about the camera sites, targets and the availability of images. Additional information of camera network and images from 2014 to 2016 can be found in Zenodo collection (https://doi.org/10.5281/zenodo.1066862). Coordinates are in decimal degrees WGS84.

\begin{tabular}{|c|c|c|c|c|c|c|c|}
\hline No. & $\begin{array}{l}\text { Site (and image } \\
\text { time period) }\end{array}$ & Lat., long. & $\begin{array}{l}\text { Altitude } \\
\text { above sea } \\
\text { (m) }\end{array}$ & $\begin{array}{l}\text { Mean annual air } \\
\text { temperature }\left({ }^{\circ} \mathrm{C}\right) \\
\text { and precipitation } \\
(\mathrm{mm})\end{array}$ & $\begin{array}{l}\text { Ecosystem/dominant } \\
\text { species }\end{array}$ & $\begin{array}{l}\text { Camera ID/position/ } \\
\text { colour space }\end{array}$ & DOI \\
\hline 1 & $\begin{array}{l}\text { Hyytiälä } \\
(2014-2016)\end{array}$ & $61.85,24.30$ & 180 & $3.5 / 711$ & Scots pine & $\begin{array}{l}\text { MC106/Crown/RGB } \\
\text { MC107/Ground/RGB }\end{array}$ & $\begin{array}{l}\text { https://doi.org/10.5281/zenodo.815559 } \\
\text { https://doi.org/10.5281/zenodo.815557 }\end{array}$ \\
\hline 2 & $\begin{array}{l}\text { Kaamanen } \\
(2015-2016)\end{array}$ & $69.14,27.27$ & $155^{\mathrm{b}}$ & $-0.4 / 472$ & Wetland & MC128/Ground/RGB & https://doi.org/10.5281/zenodo.815553 \\
\hline 3 & $\begin{array}{l}\text { Kenttärova } \\
(2015-2016)\end{array}$ & $67.99,24.24$ & $347^{\mathrm{b}}$ & $-1.0 / 521$ & Norway spruce & $\begin{array}{l}\text { MC114/Canopy/RGB } \\
\text { MC115/Crown/RGB } \\
\text { MC116/Ground/RGB }\end{array}$ & $\begin{array}{l}\text { https://doi.org/10.5281/zenodo.815519 } \\
\text { https://doi.org/10.5281/zenodo.815523 } \\
\text { https://doi.org/10.5281/zenodo.815521 }\end{array}$ \\
\hline 4 & Lammi (2016) & $61.05,25.04$ & $119^{\mathrm{a}}$ & $4.3 / 644$ & $\begin{array}{l}\text { Canopy: mixed; } \\
\text { Other cameras: } \\
\text { Downy birch }\end{array}$ & $\begin{array}{l}\text { MC122/Canopy/RGB } \\
\text { MC123/Canopy/IR } \\
\text { MC124/Landscape/RGB } \\
\text { MC125/Landscape/IR } \\
\text { MC126/Ground/RGB } \\
\text { MC127/Ground/IR }\end{array}$ & $\begin{array}{l}\text { https://doi.org/10.5281/zenodo.815538 } \\
\text { https://doi.org/10.5281/zenodo.815540 } \\
\text { https://doi.org/10.5281/zenodo. } 815542 \\
\text { https://doi.org/10.5281/zenodo. } 815544 \\
\text { https://doi.org/10.5281/zenodo.815546 } \\
\text { https://doi.org/10.5281/zenodo.815548 }\end{array}$ \\
\hline 5 & $\begin{array}{l}\text { Lompolo- } \\
\text { jänkkä (2015- } \\
\text { 2016) }\end{array}$ & $69.80,24.21$ & 274 & $-1.0 / 521^{\mathrm{b}}$ & Wetland & $\begin{array}{l}\text { MC129/Lompolojänkkä/ } \\
\text { RGB }\end{array}$ & https://doi.org/10.5281/zenodo.815555 \\
\hline 6 & $\begin{array}{l}\text { Paljakka } \\
(2015-2016)\end{array}$ & $64.68,28.11$ & $257^{\mathrm{a}}$ & $1.6 / 918^{\mathrm{c}}$ & Spruce stand & $\begin{array}{l}\text { MC117/Canopy/RGB } \\
\text { MC118/Canopy/IR } \\
{ }^{f} \text { MC117-1/ Canopy/RGB }\end{array}$ & $\begin{array}{l}\text { https://doi.org/10.5281/zenodo.815529 } \\
\text { https://doi.org/10.5281/zenodo.815527 } \\
\text { https://doi.org/10.5281/zenodo.815525 }\end{array}$ \\
\hline 7 & $\begin{array}{l}\text { Parkano }(2015- \\
2016)\end{array}$ & $62.03,23.04$ & $96^{\mathrm{a}}$ & $3.5 / 667^{b}$ & Mixed & MC112/Landscape/RGB & https://doi.org/10.5281/zenodo.815487 \\
\hline 8 & $\begin{array}{l}\text { Punkaharju } \\
(2014-2016)\end{array}$ & $61.81,29.32$ & $88^{\mathrm{a}}$ & $3.8 / 604^{\mathrm{b}}$ & Norway spruce & $\begin{array}{l}\mathrm{g}_{\mathrm{MC} 103 / \mathrm{Ground} / \mathrm{RGB}} \\
\mathrm{g}_{\mathrm{MC} 104 / \text { Crown/RGB }} \\
\mathrm{g}_{\mathrm{MC} 105 / \text { Landscape/RGB }}\end{array}$ & $\begin{array}{l}\text { https://doi.org/10.5281/zenodo.815460 } \\
\text { https://doi.org/10.5281/zenodo.815462 } \\
\text { https://doi.org/10.5281/zenodo.815464 }\end{array}$ \\
\hline 9 & $\begin{array}{l}\text { Sodankylä, } \\
\text { pine (2014- } \\
2016)\end{array}$ & $67.36,26.64$ & 179 & $-0.4 / 527^{b}$ & Scots pine & $\begin{array}{l}\text { MC108/Canopy/RGB } \\
\text { MC109/Crown/RGB } \\
\text { MC110/Ground/RGB }\end{array}$ & $\begin{array}{l}\text { https://doi.org/10.5281/zenodo.815479 } \\
\text { https://doi.org/10.5281/zenodo.815481 } \\
\text { https://doi.org/10.5281/zenodo.815483 }\end{array}$ \\
\hline 10 & $\begin{array}{l}\text { Sodankylä, } \\
\text { wetland (2014- } \\
\text { 2016) }\end{array}$ & 67.37 & 180 & $-0.4 / 527^{b}$ & Wetland & $\begin{array}{l}\text { MC111/Ground/Peatland/ } \\
\text { RGB }\end{array}$ & https://doi.org/10.5281/zenodo.815485 \\
\hline 11 & $\begin{array}{l}\text { Suonenjoki } \\
(2015-2016)\end{array}$ & $62.64,27.05$ & $135^{\mathrm{a}}$ & $3.9 / 566^{\mathrm{d}}$ & Scots pine & MC113/Canopy/RGB & https://doi.org/10.5281/zenodo.815489 \\
\hline 12 & $\begin{array}{l}\text { Tammela } \\
(2014-2016)\end{array}$ & $60.65,23.81$ & $144^{\mathrm{a}}$ & $5.4 / 601^{\mathrm{e}}$ & Norway spruce & $\begin{array}{l}\text { MC102/Ground/RGB } \\
\mathrm{h}_{\mathrm{MC} 101 / \text { Crown/RGB }} \\
\text { MC100/Canopy/RGB / }\end{array}$ & $\begin{array}{l}\text { https://doi.org/10.5281/zenodo.815456 } \\
\text { https://doi.org/10.5281/zenodo.815454 } \\
\text { https://doi.org/10.5281/zenodo.815450 }\end{array}$ \\
\hline 13 & $\begin{array}{l}\text { Tvärminne } \\
\text { (2016) }\end{array}$ & $59.84,23.25$ & 3 & $6 / 634^{b}$ & Mixed & MC130/Landscape/RGB & https://doi.org/10.5281/zenodo.815550 \\
\hline 14 & $\begin{array}{l}\text { Värriö (2015- } \\
2016)\end{array}$ & $67.75,29.61$ & 400 & $-0.5 / 601$ & Scots pine & $\begin{array}{l}\text { MC119/Canopy/RGB } \\
\text { MC120/Crown/RGB } \\
\text { MC121/Ground/RGB }\end{array}$ & $\begin{array}{l}\text { https://doi.org/10.5281/zenodo.815532 } \\
\text { https://doi.org/10.5281/zenodo.815534 } \\
\text { https://doi.org/10.5281/zenodo.815536 }\end{array}$ \\
\hline
\end{tabular}

a Altitude was determined from digital elevation model with a grid size of $10 \mathrm{~m} \times 10 \mathrm{~m}$ provided by the National Land Survey of Finland.

b Pirinen et al. (2012).

c Weather station "Puolanka Paljakka" data 2009-2017.

d FMI Precipitation station "Suonenjoki Iisvesi" data 2015-2016, temperature station measured at the site 1999-2010.

e Mean air temperature at weather station "Somero Salkola", 2011-2017; precipitation sum 1981-2010

(http://www.metla.fi/metinfo/forest-condition/programmes/intensive-monitoring.htm).

${ }^{f}$ Replaces MC117 11 February 2016 onwards.

$\mathrm{g}$ Re-positioned and refocused August 2016 after damage in June 2016

$\mathrm{h}$ Short period available from 2014 before camera damage.

\subsubsection{Hyytiälä}

The Hyytiälä site is situated at the University of Helsinki's Hyytiälä Forestry Field Station in an even-aged Scots pine (Pinus sylvestris) stand with scattered spruce and deciduous trees. One camera is focused on the pine canopy with one birch crown in view. The second camera monitors the forest floor which is dominated by dwarf shrubs and feather mosses. The camera observations are supported by a wide selection of continuous measurements of meteorology, gas 


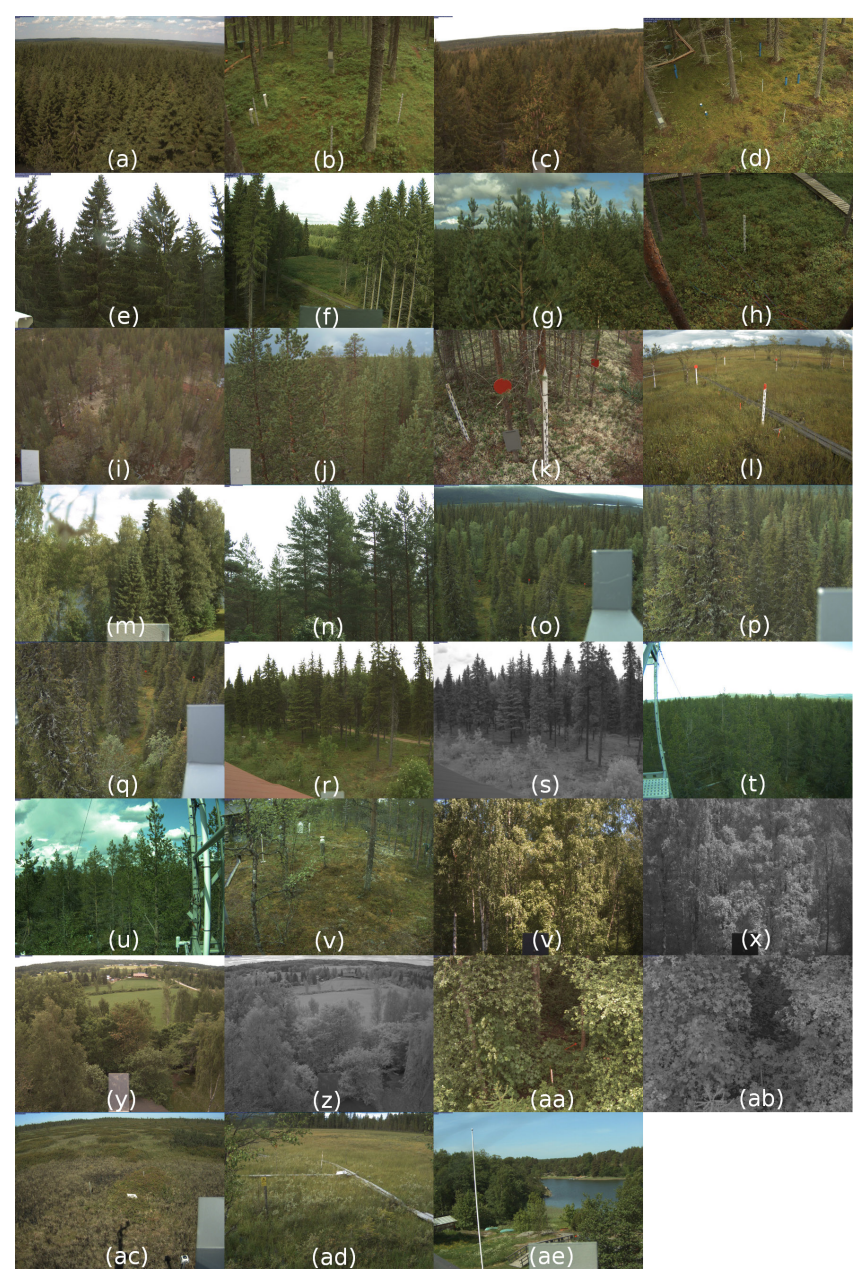

Figure 2. Camera views: MC100 (a), MC101 (b), MC102 (c), MC103 (d), MC104 (e), MC105 (f), MC106 (g), MC107 (h), MC108 (i), MC109 (j), MC110 (k), MC111 (l), MC112 (m), $\operatorname{MC} 113$ (n), MC114 (o), MC115 (p), MC116 (q), MC117 (r), $\operatorname{MC} 118$ (s), MC119 (t), MC120 (u), MC121 (v), MC122 (w), MC123 (x), MC124 (y), MC125 (z), MC126 (aa), MC127 (ab), MC128 (ac), MC129 (ad), MC130 (ae). Abbreviations refer to camera ID in Table 1.

exchange, tree ecophysiology and soil at the SMEAR II research station (Hari and Kulmala, 2005; http://www.atm. helsinki.fi/SMEAR). These data are available at AVAA portal (https://avaa.tdata.fi/web/smart/smear/).

\subsubsection{Kaamanen}

The Kaamanen wetland is an open mesotrophic fen in northern Finland, with surface pattern consisting of wet flarks and drier strings. Most of the time the flarks are inundated, but the strings with a height of approximately $0.8 \mathrm{~m}$ are constantly above the water table covering about $40 \%$ of the fen surface. The site has no permafrost, but thin lenses of ice may remain in the well-insulated strings until late summer. The flarks are covered by different sedges (Carex spp.) and moss species, while the higher strings are dominated by various shrubs, such as Ledum palustre, Empetrum nigrum, Rubus chamaemorus and Betula nana. The $\mathrm{CO}_{2}$ and $\mathrm{CH}_{4}$ fluxes between the fen and the atmosphere, as well as a variety of environmental parameters (air and soil meteorology together with different radiation components), are continuously measured at the site (Aurela et al., 2009).

\subsubsection{Kenttärova}

The Kenttärova site is situated in a Norway-sprucedominated forest at Pallas with a small number of $\mathrm{Be}$ tula pubescent also present, and is operated in conjunction with the Pallas-Sodankylä Global Atmosphere Watch station. The main species of the ground floor are Vaccinium myrtillus, Empetrum nigrum, Vaccinium vitis-idaea and the forest mosses Pleurozium schreberi, Hylocomium splendens and Dicranum polysetum. Carbon dioxide fluxes together with an extensive set of meteorological parameters are measured at the site. Kenttärova is an associated site within the ICOS flux network.

\subsubsection{Lammi}

The Lammi site is situated at University of Helsinki's Lammi Biological Station (LBS) which belongs to the Finnish LongTerm Socio-Ecological Research network (FinLTSER). The station is located in a region characterized by boreal forest, lake and agricultural landscapes. Three cameras are present (ground, crown and landscape) including deciduous species Betula pubescens, Acer platanoides, Ulmus glabra, Prunus padus, Tilia cordata and Ribes alpinum. The FMI weather station "Hämeenlinna Lammi Pappila" is located at LBS. LBS also maintains a photosynthetically active radiation sensor (data available upon request from LBS).

\subsubsection{Lompolojänkkä}

The Lompolojänkkä site is located on an open, mesotrophic sedge fen. The field layer vegetation in the wetter parts of the fen is dominated by sedges, while drier parts are characterized by fairly dense stands of Betula nana. Low shrubs can be found across the fen with relatively low coverages. For a more detailed description of Lompolojänkkä, see Aurela et al. (2009) and Lohila et al. (2010). The camera has a general view on the drier part of the fen. The $\mathrm{CO}_{2}$ and $\mathrm{CH}_{4}$ fluxes together with a set of environmental parameters (air and soil meteorology together with different radiation components) are continuously measured at the site. Kenttärova is a Class 2 site within the ICOS flux network.

\subsubsection{Paljakka}

Paljakka is a phenology monitoring site in central Finland belonging to the phenological monitoring network operating in Finland (Poikolainen et al., 1996; Pudas et al., 2008), 
where seasonal development of main tree species in Finland is monitored. The camera is located on the station roof, and is focused on a Norway spruce stand. Image view includes small birch trees that are monitored for phenology. The FMI weather station "Puolanka Paljakka" is located in the immediate vicinity of the camera.

\subsubsection{Parkano}

Paljakka is a phenology monitoring site in southern Finland, belonging to the same network of sites as Paljakka site. The camera is located at the station roof, and is focused on a mixed forest landscape including trees that are monitored for phenology, and a lake behind the trees. The FMI weather station ("Karvia Alkkia") is within approximately $20 \mathrm{~km}$ of the camera.

\subsubsection{Punkaharju}

The Punkaharju site is a mature spruce (Picea abies) stand on mesic soil. It hosts three cameras at different heights, one taking images of the ground, one at the crown level, and one taking images of the surrounding landscape. The nearest FMI weather station "Savonlinna Punkaharju Laukansaari" is within $3 \mathrm{~km}$. The Punkaharju site belongs to the ICP Forests (International Cooperative Programme on the Assessment and Monitoring of Air Pollution Effects on Forests) level II monitoring site for long-term ecosystem monitoring. A diverse set of ecosystem monitoring is conducted at the site; see ICP Forests manual for details and monitoring information collected (http://icp-forests.net/ page/icp-forests-manual; Merilä et al., 2013).

\subsubsection{Sodankylä forest}

The Scots pine (Pinus sylvestris) forest site in Sodankylä is situated within the Arctic Research Centre of the FMI. The sparse ground vegetation consists of lichens $(73 \%)$, mosses $(12 \%)$ and ericaceous shrubs $(15 \%)$. There are three cameras at this site, with views on the forest canopy, crown and the ground. Carbon dioxide fluxes together with an extensive set of meteorological parameters are measured at the site. The Sodankylä forest is a Class 1 site within the ICOS flux network.

\subsubsection{Sodankylä wetland}

The Sodankylä wetland (Halssiaapa) is an open fen in the vicinity of the Sodankylä forest flux site. It is dominated by large, treeless flarks with abundant sedge vegetation, complemented by fairly low and narrow ridges with birch trees (of 5-7 $\mathrm{m}$ in height). $\mathrm{CO}_{2}$ and $\mathrm{CH}_{4}$ fluxes as well as basic meteorological parameters are measured at the site.

\subsubsection{Suonenjoki}

The Suonenjoki site has a Scots pine (P. sylvestris) stand on sub-xeric soil. There is a weather station maintained by the Natural Resources Institute Finland at the site (data on request from the corresponding author). The nearest FMI weather station "Suonenjoki Iisvesi" is within $3 \mathrm{~km}$ distance. No other monitoring actions are conducted at this site.

\subsubsection{Tammela}

The site presently hosts two cameras, one taking images of the ground and another taking images of the surrounding landscape. The Tammela site has a mature spruce $(P$. abies) stand on mesic soil. It belongs to the network of ICP Forests level II sites. Consult ICP II Forests manual for permanent monitoring data collected (http://icp-forests.net/ page/icp-forests-manual). The FMI weather station "Somero Salkola" is also at the site.

\subsubsection{Tvärminne}

The Tvärminne site belongs to the Finnish Long-Term SocioEcological Research network (FinLTSER) and is located at the western Gulf of Finland at the University of Helsinki's Tvärminne Zoological Station. The area was post-glacially uplifted above the sea level and is characterized by a mix of bedrock and clay soil material and herb-rich forest (nemoral) forest. One camera is installed on the roof of the station's main building viewing the landscape at the shoreline of the archipelago (Fig. 2ae). The camera allows the monitoring of the tree phenology, the seasonal development of reeds and the evolution of sea ice. The tree species in the camera's field of view include elm (Ulmus glabra), maple (A. platanoides), downy birch (B. pubescens), ash (Fraxinus excelsior), common alder (Alnus glutinosa) and Scots pine (P. sylvestris L.). The FMI weather station "Hanko-Tvärminne" is located at the site and provides measurements of air temperature, precipitation, humidity and snow depth.

\subsubsection{Värriö}

The Värriö site is located in Salla, eastern Lapland, at the northern alpine timberline on the summit plateau of a hill. The relatively open forest stand is dominated by Scots pine (P. sylvestris) of various age with occasional mountain birch (Betula pubescens var. punilla) in the understorey. The forest floor vegetation consists of a variety of mosses, lichens and dwarf shrubs. The site accommodates three cameras for taking images of the landscape, the pine crowns and the forest floor. The cameras are part of SMEAR I research station (Hari et al., 1994; http://www.atm.helsinki.fi/SMEAR) where continuous measurements of meteorology, gas exchange, tree ecophysiology and soil are performed. The data are available at AVAA portal (https://avaa.tdata.fi/web/smart/ smear/). 


\section{Examples of processed image data}

Here we show examples of the data collected within our network, focusing on the effect of systematic change in illumination conditions during the annual cycle of solar elevation known to influence colour spectra of incoming radiation, which potentially affects the calculated colour ratios in images. The analyses were done for five regions of interest (ROI) of camera views at two contrasting sites separated by $10^{\circ}$ latitude (Fig. 3).

Mean green fraction of regions of interest (vegetation) in images has been found to vary by illumination conditions (Ahrends et al., 2009). It has been reported that the systematic changes of image-based colour indices during the season can be largely omitted by focusing the analyses on midday images (Ahrends et al., 2009), possibly by aggregating information from nearby days (Sonnentag et al., 2012), and by selecting a robust estimator that is aggregated, e.g. median. Colour changes in deciduous vegetation and snow cover over the season are distinctive enough to be clearly depicted behind the day-to-day variation due to clouds and irradiation (Peltoniemi et al., 2018; Arslan et al., 2017), but in wetlands and coniferous trees these differences can be more obscure.

We calculated mean green chromatic coordinates $(\mathrm{GCC}=\mathrm{G} /(\mathrm{R}+\mathrm{G}+\mathrm{B})$, for pixels in the region of interest (ROI). Individual pixels were accepted for the mean calculation if exposure was sufficient - i.e. pixels were not poorly exposed or overexposed (Sonnentag et al., 2012). We required that pixel digital numbers for $\mathrm{R}, \mathrm{G}$ and $\mathrm{B}$ were all in the range $[30,254]$. Daily images were classified to classes 1, 2 and 3, based on Sun elevation angles falling into categories $>30^{\circ}\left[20,30^{\circ}\right),\left(0,20^{\circ}\right)$, respectively. Daily medians of GCC in these groups were calculated. Sun elevation angles were calculated using coordinates and time of day. In addition to these Sun elevation class medians, we also calculated daily median from midday images between 10:00 and 14:00 UTC + 2. Daily time series of GCC were subsequently smoothed with loess regression so as to present interpolated daily estimates because the number of the images for median calculation was small.

As Kaamanen is a northern site with no daylight during the winter time, there is a long gap in image data (Fig. 4). The overall trend in the phenological development of the birch (B. pubescens) and other wetland vegetation (mosses, sedges, shrubs) is very similar among the Sun elevation categories. The differences between these classes are clearly smaller than any changes related to phenological greening up of mosses and other wetland vegetation and even more limited than the increase of GCC due to budburst of dwarf birches (mid-May to early July). The effect of snowmelt is seen as a quick decline of GCC in Birch and Wetland GCC in early May of 2015 and 2016. A reference panel shows variable response during the time period of November to April. The panel was not snow covered in April (inspected visually from images), which implies that the variable response of the

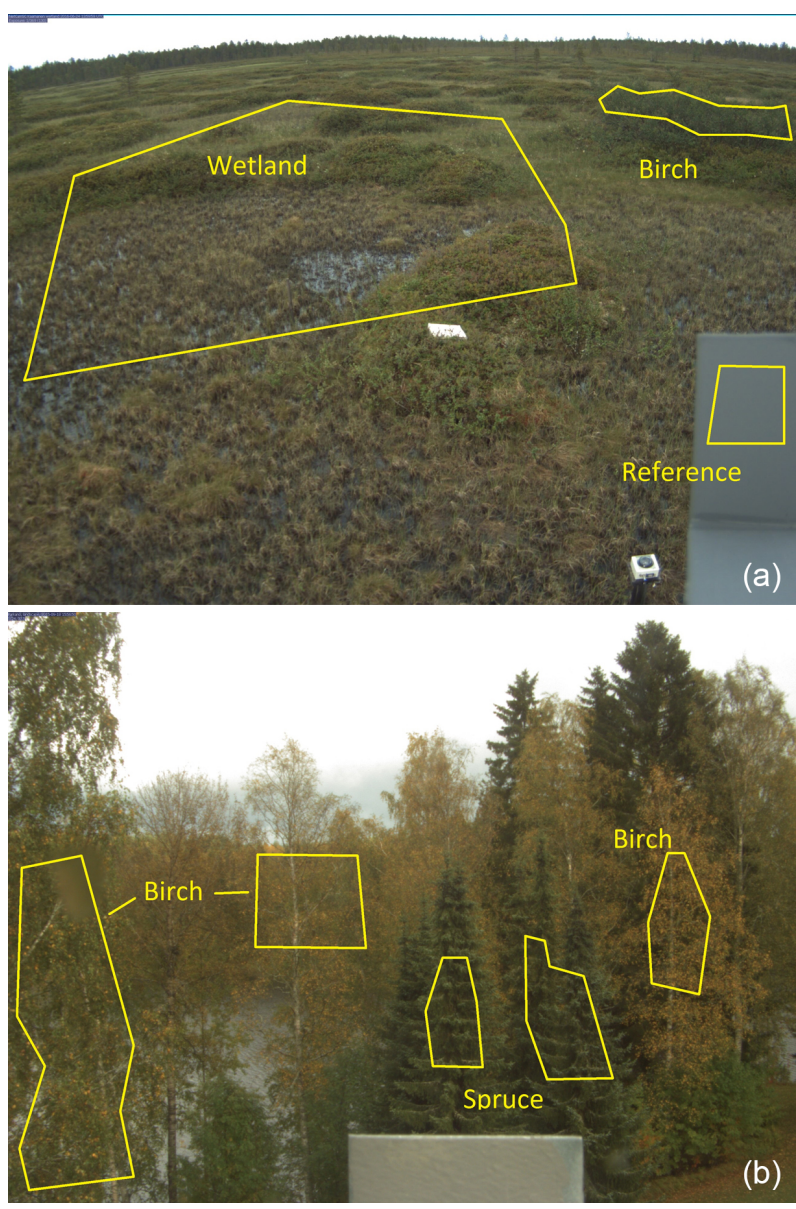

Figure 3. Regions of interest used in GCC time series construction. (a) Kaamanen wetland site (camera MC128), with Sphagnum spp and grasses (Wetland ROI), shrubs like pubescent birch (Betula pubescens subsp. Czerepanovii) (birch), and reference grey plate. (b) Parkano site (camera MC112), with silver birches (Betula pendula) ROI distributed in three separated polygons (birch), and Norway spruce (Picea abies L. Karst) ROI.

panel's colour index may reflect the profound change of the light environment due to snow melt of the surroundings and multiple reflections.

Located in southern Finland, Parkano has gaps in the data during the winter only in the classes 1 and 2 (Fig. 5) because of higher Sun elevations during the winter. Again all categories of Sun elevation give similar overall development of GCC, including midday median. The greenness change from winter to summer is nearly as much for the planted non-native Serbian spruce (P. omorika) as it is for birch $(B$. pendula). However, GCC estimated for spruce by Sun elevation class shows across class differences and lower GCC for higher Sun elevation angles, which could be related to the darker surface of spruces foliage and how colour ratios are reproduced at low digital numbers in the shaded parts of the canopy. Canopy geometry and camera orientation affect how the shaded parts are detected by the camera, which suggests 


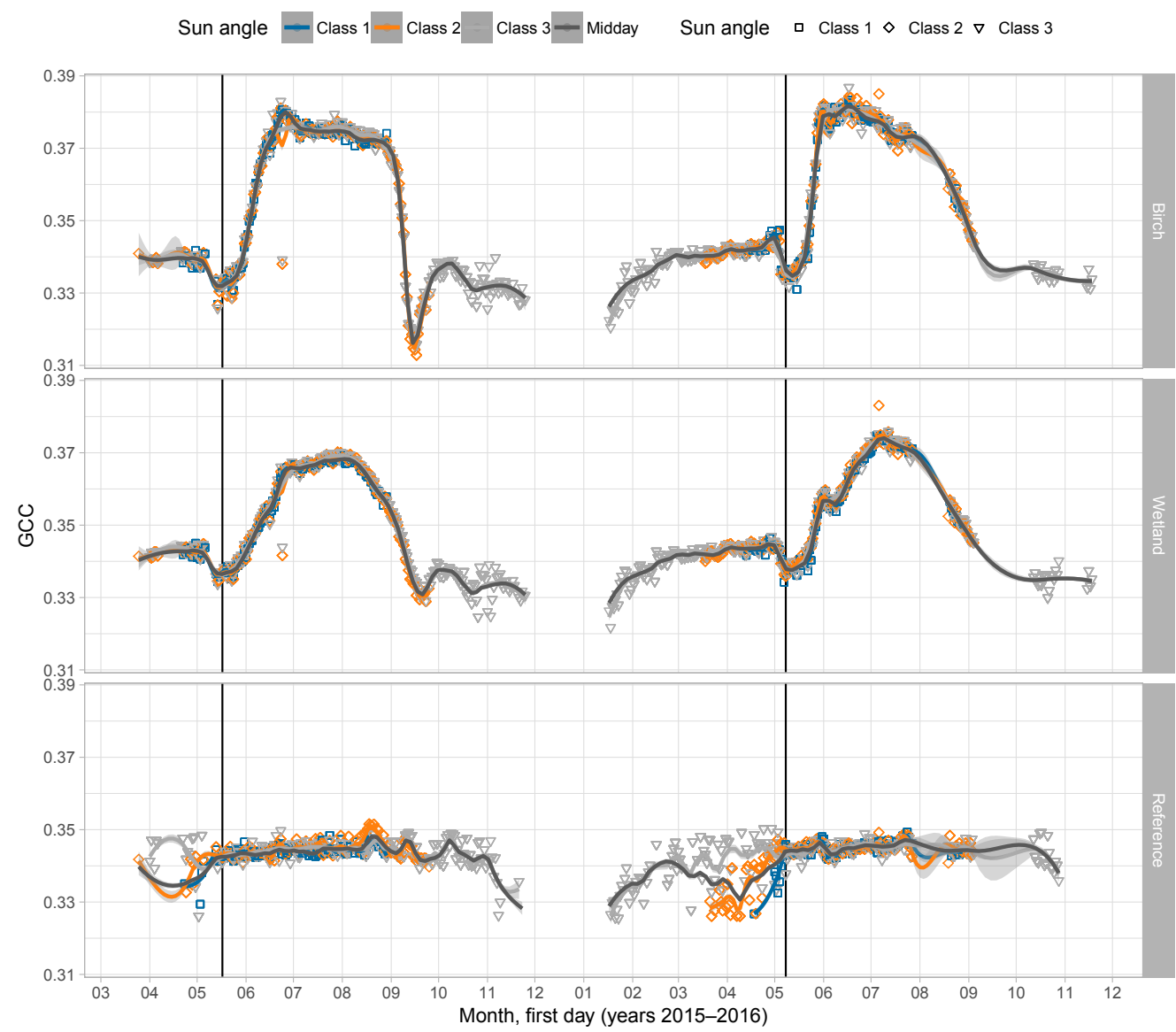

Figure 4. Daily GCC time series of ROI in Kaamanen site by solar elevation category - class $1:>30^{\circ}$; class $2:\left(20,30^{\circ}\right)$; class $3:(0$, $20^{\circ}$ ) - and as daytime averages (midday: 10:00-14:00 UTC + 2) and smoothed development of GCC over the years. Vertical line shows the snowmelt date, i.e. the first day without any snow.

that differences in GCC due to Sun angle could be sensitive to these configurations. Overall, our results confirm the earlier conclusions recommending the use of midday images for daily aggregation and filtering of phenological time series by several authors (Sonnentag et al., 2012; Wingate et al., 2015; Filippa et al., 2016).

\section{Data availability}

To distribute images, we established a community (Phenological time lapse images and data from Monimet EU Life+ project (LIFE12 ENV/FI/000409), https://www.zenodo.org/ communities/phenology_camera/) in Zenodo repository service (https://www.zenodo.org/) maintained by CERN. The service was established in the EU OpenAIRE project (https: //www.openaire.eu/) and is meant for permanent archiving and distribution of research materials.

The images from each camera covers the period between 2014 and 2016 or parts of it (Fig. 6). Images are in their original quality, and have not been qual- ity checked. Only known major status issues influencing analyses are reported in the associated camera datasheet (https://doi.org/10.5281/zenodo.1066862; Peltoniemi et al., 2017). Users are welcomed to report new status issues with the images to their contact persons (see camera datasheet). Temporal coverage of images varies by site and camera, depending on the mounting date, and data connection variability at the sites, which occasionally terminates half-hourly submissions of the images to the FTP server in remote locations when cameras are on a mobile phone network.

Images are organized in camera-specific collections available in our Zenodo community, each having their unique DOI-number. Collections include images from each camera from 2014 to 2016 packed into a zip file, named after camera ID and years of coverage. DOI of image zips are listed in Table 1. Image files names include the information about the location, target, date and capture time of the image and follow the format <location $>$ _target $>$ _ $<Y Y Y Y M M D D><<H H M M S S>$.jpg. If the 


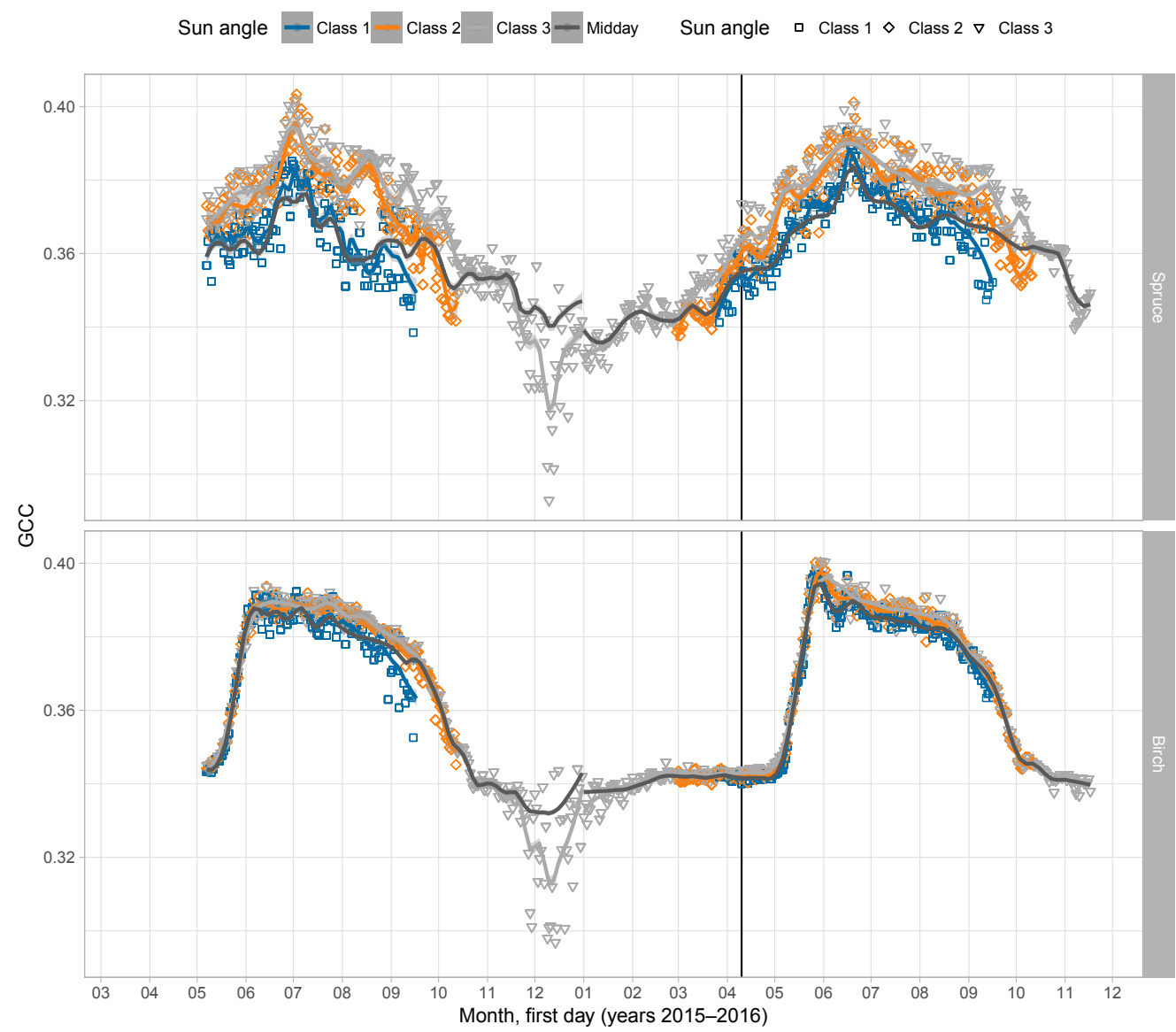

Figure 5. Daily GCC time series of ROI in Parkano site by solar elevation category - class 1: $>30^{\circ}$; class $2:\left(20,30^{\circ}\right)$; class $3:\left(0,20^{\circ}\right)-$ and as daytime averages (midday: 10:00-14:00 UTC + 2) and smoothed development of GCC over the years. Vertical line shows the snowmelt date, i.e. the first day without any snow. In 2015 snow had melted before the camera was installed.

image is captured in IR format it is indicated by an additional tag $<$ _IR $>$ before the date and time.

Camera-specific information is available in the camera datasheet also stored in Zenodo. For the present submission of 2014-2016 images of cameras in the Table 1, see the camera datasheet (https://doi.org/10.5281/zenodo.1066862). We plan to update the collection of images in the future, by adding new versions of the image datasets. For newer images not yet uploaded to Zenodo, please contact camera contact persons in the datasheet, and metadata of present camera image uploads.

Material in the database is published under Creative Commons Attribute 4.0 license.

\section{Conclusions}

Digital cameras have shown their value in various phenological applications. They gather valuable information, which can be analysed for scientific purposes, particularly for those addressing changes in time. Here, we have presented a cam- era network operating in Finland, with cameras mounted in sites ranging from hemiboreal to subarctic regions. So far, we have used the cameras in the analyses of latitudinal trends of birch phenology (Peltoniemi et al., 2018), snow cover (Arslan et al., 2017), and analyses of Scots pine and wetland $\mathrm{CO}_{2}$ fluxes (Linkosalmi et al., 2016) with encouraging results. Several possibilities for further research exist, particularly associated with temporal changes of colours in conifer canopies, and changes of snow cover.

So far, mostly simple analyses based on colours have been used in phenological and snow analyses, and we find them useful in tracking seasonal phenomena, particularly as they have been shown to be robust to light conditions here and elsewhere (Ahrends et al., 2009). Some aspects of colour analysis require further research, including the role of light scattering from snow and associated light environment change, which seems to complicate analyses of colour ratio changes of vegetation targets. Some of these challenges could be overcome by combining radiation transfer approaches to image analyses (Wingate et al., 2015). 


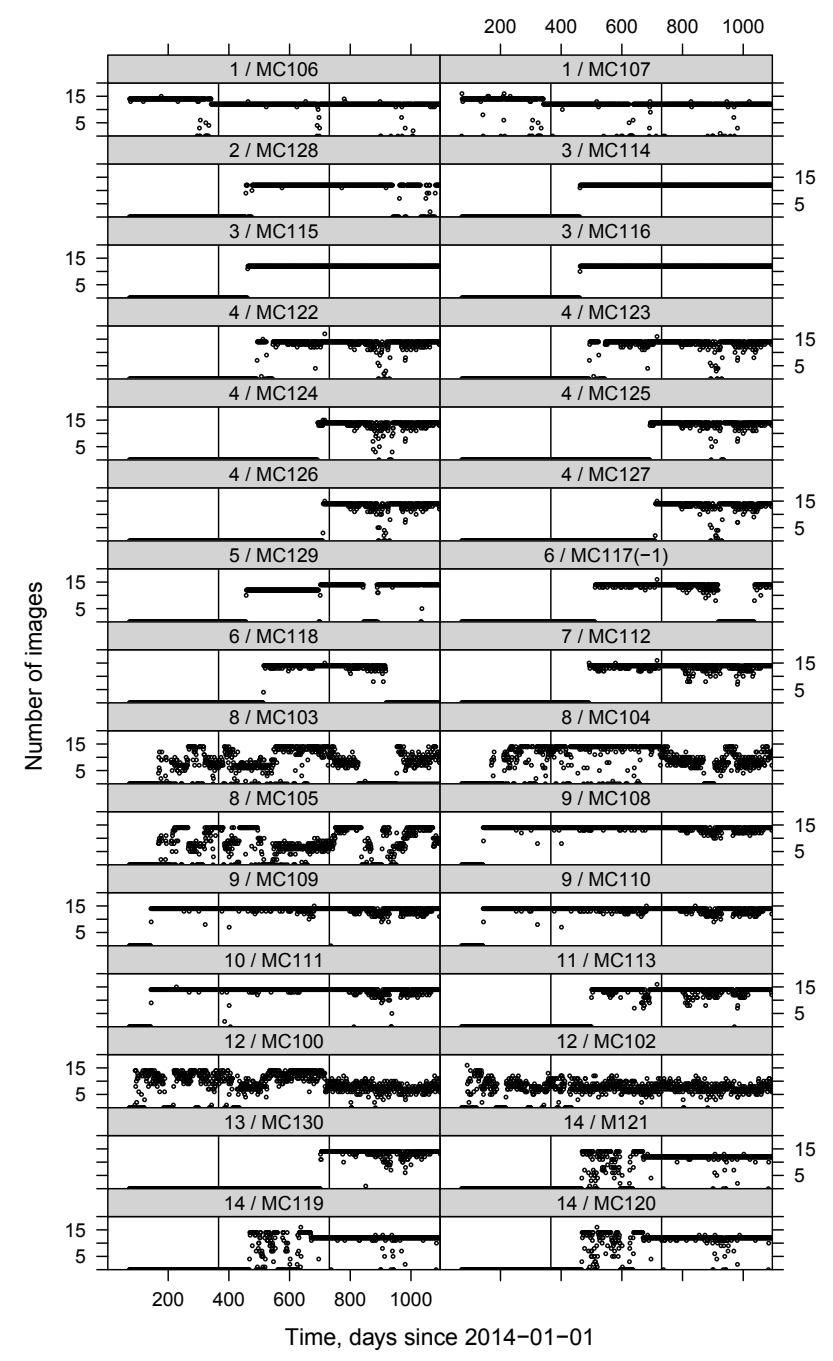

Figure 6. Number of images taken between 09:00 and 15:00 UTC +2 . The image archive contains images from longer period during the day. Cameras do not take images during night hours. Site labels refer to Table 1 .

It is also interesting to note that image analyses and tools are developing quickly. Efficient image processing libraries are available in many languages, e.g. in $\mathrm{C}++(\mathrm{OpenCV}$, with bindings in Python), and also in higher-level languages such as R and Python, rendering them useful for any researcher. For example, $\mathrm{R}$ libraries such as greenbrown and phenopix group statistical methods useful for phenological analyses of images (Forkel and Wutzler, 2015; Filippa et al., 2016). Research on the automation of more complex analyses based on structural features could allow more possibilities and more reliable quantification of phenological and snow events and that vary by position within the image view, possibly automating a large part of the analyses (Filippa et al., 2016).

While cameras are easy to deploy and they operate nearly autonomously, they still require maintenance. The surveil- lance cameras used in this study required direct wiring to an electrical grid for sufficient power (Power over Ethernet or separate power cabling). Other types of cameras consume less power, and could operate on batteries for long periods. Based on our experiences, the most critical factors preventing data capture are associated with camera mounting and the use of mobile networks in remote areas. Over 3 years of operating 28 cameras, only three cameras have become unresponsive: one possibly due to lightning and one possibly due to failure of cabling. Camera views have shifted significantly on three occasions due to mounting failures. The protective glass at the front of camera boxes has been broken three times, twice likely due to temperature variation and once likely due to damage caused by a human or a large bird. Easy access to cameras obviously facilitates occasional maintenance operations. If enough attention has been paid to the solid mounting of the cameras to avoid camera view shifts, and image backups are configured to local storage when cameras are operated over weak networks, cameras offer interesting time series for the continuous analyses of phenology.

Networked cameras can be used for obtaining broad spatial information about ecosystem status, and thus to support Earth observation and carbon balance and hydrological analyses. Inevitably, the spatial coverage of cameras deployed at research sites remains limited, so other means of extending the spatial coverage should also be considered. Increasingly, the number of cameras plugged into the internet by citizens and other actors outside the research community (see Morris et al., 2013) could be useful for these purposes. These cameras rarely follow restrictions or recommendations of phenological camera networks, but they could still provide useful material for global mapping of vegetation and snow. Networked cameras at research sites providing quality-assured material on phenological progress could support analyses of even wider networks of cameras using approaches based on machine learning and artificial intelligence.

Author contributions. MP coordinated the design of the network. MP, MA, PK, KB, and ANA participated in the design of the network and this study. Funding was acquired by ANA (coordinator), MP, and $\mathrm{KB}$. MP, MA, PK, KB, and JL are responsible for site-specific installations. MP wrote the study and MA, PK, KB, ANA, JPT, JL, and CMT contributed to the text. ML and JK participated in installations of cameras with other authors.

Competing interests. The authors declare that they have no conflict of interest.

Disclaimer. The authors do not perform quality control of images. Experiences with data are collected by individual studies, and the authors request users to report their experience to the authors. 
Acknowledgements. This work was carried out with contribution from the LIFE+ financial instrument of the European Union (LIFE12 ENV/FI/000409 Monimet, http://monimet.fmi.fi). We thank Joanna Norkko and Antti Nevalainen (University of Helsinki) for help in installations in Tvärminne research station, Jussi Vuorenmaa (SYKE) and Martin Forsius (SYKE) for discussions about installations of cameras to FinLTSER sites and Timo Vesala (University of Helsinki) and Tuomas Laurila (FMI) and Päivi Merilä (Luke) for facilitating installations. We also thank Ari Ryynänen, Esko Oksa and Jouni Karhu for installations in Parkano, Tammela and Punkaharju and Paljakka sites, and Juuso Rainne (FMI) and Janne Levula (University of Helsinki) in Hyytiälä.

Edited by: David Carlson

Reviewed by: two anonymous referees

\section{References}

Ahrends, H. E., Etzold, S., Kutsch, W. L., Stoeckli, R., Bruegger, R., Jeanneret, F., Wanner, H., Buchmann, N., and Eugster, W.: Tree phenology and carbon dioxide fluxes: use of digital photography for process-based interpretation at the ecosystem scale, Clim. Res., 39, 261-274, 2009.

Arslan, A. N., Tanis, C. M., Metsämäki, S., Aurela, M., Böttcher, K., Linkosalmi, M., and Peltoniemi, M.: Automated Webcam Monitoring of Fractional Snow Cover in Northern Boreal Conditions, Geosciences, 7, 55, https://doi.org/10.3390/geosciences7030055, 2017.

Aurela, M., Lohila, A., Tuovinen, J., Hatakka, J., Riutta, T., and Laurila, T.: Carbon dioxide exchange on a northern boreal fen, Boreal Environ. Res., 14, 699-710, 2009.

Basler, D.: Evaluating phenological models for the prediction of leaf-out dates in six temperate tree species across central Europe, Agr. Forest Meteorol., 217, 10-21, 2016.

Brown, T. B., Hultine, K. R., Steltzer, H., Denny, E. G., Denslow, M. W., Granados, J., Henderson, S., Moore, D., Nagai, S., SanClements, M., Sánchez-Azofeifa, A., Sonnentag, O., Tazik, D., and Richardson, A. D.: Using phenocams to monitor our changing Earth: toward a global phenocam network, Front. Ecol. Environ., 14, 84-93, 2016.

Elmore, A. J., Guinn, S. M., Minsley, B. J., and Richardson, A. D.: Landscape controls on the timing of spring, autumn, and growing season length in mid-Atlantic forests, Glob. Change Biol., 18, 656-674, 2012.

Filippa, G., Cremonese, E., Migliavacca, M., Galvagno, M., Forkel, M., Wingate, L., Tomelleri, E., Morra di Cella, U., and Richardson, A. D.: Phenopix: A R package for image-based vegetation phenology, Agr. Forest Meteorol., 220, 141-150, 2016.

Forkel, M. and Wutzler, T.: greenbrown - land surface phenology and trend analysis. A package for the R software., Version 2.2, 2015-04-15, available at: http://greenbrown.r-forge. r-project.org/ (last access: 23 January 2018), 2015.

Häkkinen, R.: Analysis of bud-development theories based on longterm phenological and air temperature time series: application to Betula sp. leaves, PhD thesis, Finnish Forest Research Institute, Research Papers 754, available at: http://urn.fi/URN:ISBN: 951-40-1709-9 (last access: 23 January 2018), 1999.
Hari, P. and Kulmala, M.: Station for Measuring EcosystemAtmosphere relations, Boreal Environ. Res., 10, 315-322, 2005.

Hari, P., Kulmala, M., Pohja, T., Lahti, T., Siivola, E., Palva, L., Aalto, P., Hämeri, K., Vesala, T., Luoma, S., and Pulliainen, E.: Air pollution in eastern Lapland : challenge for an environmental measurement station, Silva Fenn., 28, 29-39, 1994.

Hufkens, K., Friedl, M., Sonnentag, O., Braswell, B. H., Milliman, T., and Richardson, A. D.: Linking near-surface and satellite remote sensing measurements of deciduous broadleaf forest phenology, Remote Sens. Environ., 117, 307-321, 2012.

Keenan, T. F., Darby, B., Felts, E., Sonnentag, O., Friedl, M. A., Hufkens, K., O'Keefe, J., Klosterman, S., Munger, J. W., Toomey, M., and Richardson, A. D.: Tracking forest phenology and seasonal physiology using digital repeat photography: a critical assessment, Ecol. Appl., 24, 1478-1489, 2014.

Klosterman, S. T., Hufkens, K., Gray, J. M., Melaas, E., Sonnentag, O., Lavine, I., Mitchell, L., Norman, R., Friedl, M. A., and Richardson, A. D.: Evaluating remote sensing of deciduous forest phenology at multiple spatial scales using PhenoCam imagery, Biogeosciences, 11, 4305-4320, https://doi.org/10.5194/bg-11-4305-2014, 2014.

Linkosalmi, M., Aurela, M., Tuovinen, J.-P., Peltoniemi, M., Tanis, C. M., Arslan, A. N., Kolari, P., Böttcher, K., Aalto, T., Rainne, J., Hatakka, J., and Laurila, T.: Digital photography for assessing the link between vegetation phenology and $\mathrm{CO}_{2}$ exchange in two contrasting northern ecosystems, Geosci. Instrum. Meth., 5, 417426, 2016.

Lohila, A., Aurela, M., Hatakka, J., Pihlatie, M., Minkkinen, K., Penttilä, T., and Laurila, T.: Responses of $\mathrm{N}_{2} \mathrm{O}$ fluxes to temperature, water table and $\mathrm{N}$ deposition in a northern boreal fen, Eur. J. Soil Sci., 61, 651-661, 2010.

Merilä, P., Ukonmaanaho, L., Nöjd, P., and Beuker, E.: Intensive and continuous monitoring of forest ecosystems - Level II in Finland, in: Forest Condition Monitoring in Finland - National report. The Finnish Forest Research Institute, edited by: Merilä, P. and Jortikka, S., available at: http://urn.fi/URN:NBN:fi: metla-201305087571 (last access: 23 January 2018), 2013.

Migliavacca, M., Galvagno, M., Cremonese, E., Rossini, M., Meroni, M., Sonnentag, O., Cogliati, S., Manca, G., Diotri, F., Busetto, L., Cescatti, A., Colombo, R., Fava, F., Morra di Cella, U., Pari, E., Siniscalco, C., and Richardson, A. D.: Using digital repeat photography and eddy covariance data to model grassland phenology and photosynthetic $\mathrm{CO}_{2}$ uptake, Agr. Forest Meteorol., 151, 1325-1337, 2011.

Mizunuma, T., Wilkinson, M., Eaton, E. L., Mencuccini, M., Morison, J. I. L., and Grace, J.: The relationship between carbon dioxide uptake and canopy colour from two camera systems in a deciduous forest in southern England, Funct. Ecol., 27, 196-207, 2013.

Morisette, J. T., Richardson, A. D., Knapp, A. K., Fisher, J. I., Graham, E. A., Abatzoglou, J., Wilson, B. E., Breshears, D. D., Henebry, G. M., Hanes, J. M., and Liang, L.: Tracking the rhythm of the seasons in the face of global change: phenological research in the 21st century, Front. Ecol. Environ., 7, 253-260, 2009.

Morris, D. E., Boyd, D. S., Crowe, J. A., Johnson, C. S., and Smith, K. L.: Exploring the Potential for Automatic Extraction of Vegetation Phenological Metrics from Traffic Webcams, Remote Sens., 5, 2200-2218, 2013. 
Nagai, S., Saitoh, T. M., Kobayashi, H., Ishihara, M., Suzuki, R., Motohka, T., Nasahara, K. N., and Muraoka, H.: In situ examination of the relationship between various vegetation indices and canopy phenology in an evergreen coniferous forest, Japan, Int. J. Remote Sens., 33, 6202-6214, 2012.

Nasahara, K. N. and Nagai, S.: Review: Development of an in situ observation network for terrestrial ecological remote sensing: the Phenological Eyes Network (PEN), Ecol. Res., 30, 211-223, 2015.

Peichl, M., Sonnentag, O., and Nilsson, M. B.: Bringing Color into the Picture: Using Digital Repeat Photography to Investigate Phenology Controls of the Carbon Dioxide Exchange in a Boreal Mire, Ecosystems, 18, 115-131, 2015.

Peltoniemi, M., Aurela, M., Böttcher, K., Kolari, P., Linkosalmi, M., Loehr, J., Tanis, C. M., and Arslan, A. N.: Datasheet of ecosystem cameras installed in Finland in Monimet Life+ project, Zenodo, https://doi.org/10.5281/zenodo.1066862, 2017.

Peltoniemi, M., Aurela, M., Böttcher, K., Kolari, P., Loehr, J., Hokkanen, T., Karhu, J., Tanis, C. M., Metsämäki, S., Tuovinen, J., Vesala, T., and Arslan, A. N.: Networked web-cameras monitor congruent seasonal development of birches with phenological field observations, Agr. Forest Meteorol., 249, 335-347, https://doi.org/10.1016/j.agrformet.2017.10.008, 2018.

Pirinen, P., Simola, H., Aalto, J., Kaukoranta, J. P., Karlsson, P., and Ruuhela, R.: Tilastoja Suomen ilmastosta 1981-2010, Ilmatieteenlaitos, Finnish Meteorological institute, Raportteja - Rapporter - Reports, vol. 1, 1-96, available at: http://hdl.handle.net/ 10138/35880 (last access: 23 January 2018), 2012.

Poikolainen, J., Karhu, J., and Kubin, E.: Development of a plantphenological observation network in Finland, Finnish Forest Research Institute, Research Papers, 623, 97-101, 1996.

Pudas, E., Leppälä, M., Tolvanen, A., Poikolainen, J., Venäläinen, A., and Kubin, E.: Trends in phenology of Betula pubescens across the boreal zone in Finland, Int. J. Biometeorol., 52, 251259, 2008.

Richardson, A. D., Jenkins, J. P., Braswell, B. H., Hollinger, D. Y., Ollinger, S. V., and Smith, M.: Use of digital webcam images to track spring green-up in a deciduous broadleaf forest, Oecologia, 152, 323-334, 2007.

Richardson, A. D., Braswell, B. H., Hollinger, D. Y., Jenkins, J. P., and Ollinger, S. V.: Near-surface remote sensing of spatial and temporal variation in canopy phenology, Ecol. Appl., 19, 14171428, 2009.
Richardson, A. D., Keenan, T. F., Migliavacca, M., Ryu, Y., Sonnentag, O., and Toomey, M.: Climate change, phenology, and phenological control of vegetation feedbacks to the climate system, Agr. Forest Meteorol., 169, 156-173, 2013.

Salvatori, R., Plini, P., Giusto, M., Valt, M., Salzano, R., Montagnoli, M., Cagnati, A., Crepaz, G., and Sigismondi, D.: Snow cover monitoring with images from digital camera systems, Ital. J. Remote Sens., 43, 137-145, 2011.

Sonnentag, O., Hufkens, K., Teshera-Sterne, C., Young, A. M., Friedl, M., Braswell, B. H., Milliman, T., O'Keefe, J., and Richardson, A. D.: Digital repeat photography for phenological research in forest ecosystems, Agr. Forest Meteorol., 152, 159177, 2012.

Westergaard-Nielsen, A., Lund, M., Hansen, B. U., and Tamstorf, M. P.: Camera derived vegetation greenness index as proxy for gross primary production in a low Arctic wetland area, ISPRS J. Photogramm., 86, 89-99, 2013.

Wingate, L., Ogée, J., Cremonese, E., Filippa, G., Mizunuma, T., Migliavacca, M., Moisy, C., Wilkinson, M., Moureaux, C., Wohlfahrt, G., Hammerle, A., Hörtnagl, L., Gimeno, C., PorcarCastell, A., Galvagno, M., Nakaji, T., Morison, J., Kolle, O., Knohl, A., Kutsch, W., Kolari, P., Nikinmaa, E., Ibrom, A., Gielen, B., Eugster, W., Balzarolo, M., Papale, D., Klumpp, K., Köstner, B., Grünwald, T., Joffre, R., Ourcival, J.-M., Hellstrom, M., Lindroth, A., George, C., Longdoz, B., Genty, B., Levula, J., Heinesch, B., Sprintsin, M., Yakir, D., Manise, T., Guyon, D., Ahrends, H., Plaza-Aguilar, A., Guan, J. H., and Grace, J.: Interpreting canopy development and physiology using a European phenology camera network at flux sites, Biogeosciences, 12, 5995-6015, https://doi.org/10.5194/bg-12-5995-2015, 2015.

Yang, X., Tang, J., and Mustard, J. F.: Beyond leaf color: Comparing camera-based phenological metrics with leaf biochemical, biophysical, and spectral properties throughout the growing season of a temperate deciduous forest, J. Geophys. Res.-Biogeo., 119, 181-191, 2014.

Zhang, X., Friedl, M. A., and Schaaf, C. B.: Global vegetation phenology from Moderate Resolution Imaging Spectroradiometer (MODIS): Evaluation of global patterns and comparison with in situ measurements, J. Geophys. Res.-Biogeo., 111, G04017, https://doi.org/10.1029/2006JG000217, 2006. 